\title{
Peramalan Penjualan Hijab Sxproject Menggunakan Metode Moving Average dan Exponential Smoothing
}

\author{
Khamaludin $^{1)}$ Vitara Agustianna ${ }^{2)}$ Aji $\operatorname{Darmawan}^{3)}$ M. Laedy Dermawan ${ }^{4)}$ \\ Jurusan Teknik Informatika, Fakultas Teknik, Universitas Islam Syekh Yusuf, Jl. Mulana Yusuf No.10 Tangerang \\ Banten 15118, Indonesia \\ 1)khamaludin@unis.ac.id \\ 2) vitaraagustian@ gmail.com \\ 3) ajidarmawan65@gmail.com \\ 4) laedydermawan170@gmail.com
}

\begin{abstract}
Abstrak. Penjualan hijab online di Indonesia sedang mengalami kenaikan yang cukup pesat. Penjual hijab online merajalela di situs-situs e-commerce salah satunya online shop sxproject ini. Selain peningkatan pada banyaknya penjual hijab, peningkatan juga terjadi pada konsumen pengguna hijab itu sendiri. Dengan tingginya peminat hijab, penjual atau produsen harus menyiasati produksi penjualan mereka agar dapat mencapai target dan tidak membuat stok terlalu banyak. Untuk mengetahui berapa yang harus diproduksi oleh penjual pada tahun berikutnya, penjual dapat melakukan perhitungan peramalan. Berdasarkan perhitungan dengan menggunakan metode rata-rata bergerak dan penghalusan eksponensial dengan tingkat kesalahan menggunakan MAD, MSE, dan MAPE. Berdasarkan perhitungan dengan dua metode tersebut dan tingkat kesalahan diperoleh metode terbaiknya adalah metode rata-rata bergerak 4 bulan.
\end{abstract}

Kata kunci: penghalusan eksponensial, penjualan, peramalan, rata-rata bergerak,

\begin{abstract}
Online hijab sales in Indonesia are experiencing a pretty rapid increase. Online hijab sellers are rampant on e-commerce sites, one of them is sxproject online shop. In addition to an increase in the number of hijab sellers, the increase also occurred in consumers who use the hijab. With the high demand for hijab, sellers or producers have to get around their production sales in order to reach the target and not make too much stock. To find out how much should be produced by the seller in the following year, the seller can do forecasting. Based on calculations using the Moving average method and Exponential Smoothing with error rates using MAD, MSE, and MAPE. Based on calculations with these two methods and the error rate obtained the best method is the 4-month Moving average method.
\end{abstract}

Keywords: Exponential Smoothing, selling, forecasting, moving average

\section{Pendahuluan}

Penjualan suatu produk bertujuan untuk mendapatkan keuntungan sebanyak-banyaknya dengan biaya sekecil mungkin. Penjual akan melakukan berbagai cara untuk memaksimalkan produknya terjual. Setiap penjual mempunyai caracara tertentu dalam menentukan berapa banyak produk yang harus mereka produksi agar mencapai target penjualan. Perhitungan peramalan merupakan salah satu metode untuk memperkirakan jumlah produk yang akan dijual. Tujuan dari perhitungan ini adalah mampu meramalkan penjualan pada periode selanjutnya dengan melihat data penjual dari periode sebelumnya. Perhitungan ini juga mempertimbangkan kesalahan-kesalahan yang terjadi saat perhitungan peramalan dengan menggunakan metode perhitungan kesalahan.

Kegiatan peramalan merupakan bagian integral dari pengambilan keputusan manajemen. Peramalan mengurangi ketergantungan pada hal-hal yang belum pasti (intuitif). Peramalan memiliki sifat saling ketergantungan antar divisi atau bagian. Kesalahan dalam proyeksi penjualan akan mempengaruhi pada ramalan anggaran, pengeluaran operasi, arus kas, persediaan, dan sebagainya.

Terdapat dua pendekatan untuk melakukan peramalan yaitu dengan pendekatan kualitatif dan pendekatan kuantitatif. Metode peramalan kualitatif digunakan ketika data historis tidak tersedia. Metode peramalan kualitatif adalah metode subyektif (intuitif). Metode ini didasarkan pada informasi kualitatif. Dasar informasi ini dapat memprediksi kejadiankejadian di masa yang akan datang. Penggunaan berbagai model peramalan akan memberikan nilai ramalan yang berbeda dan derajat dari galat ramalan (forecast error) yang berbeda pula. Seni dalam melakukan peramalan adalah memilih model peramalan terbaik yang mampu mengidentifikasi dan 
menanggapi pola aktivitas historis dari data. Modelmodel peramalan dapat dikelompokan ke dalam dua kelompok utama, yaitu metode kualitatif dan metode kuantitatif. Metode kuantitatif dikelompokkan menjadi dua kelompok utama, yaitu intrinsik dan ekstrinsik. Metode kualitatif ditujukan untuk peramalan terhadap produk baru, pasar baru, proses baru, perubahan sosial dari masyarakat, perubahan teknologi, atau penyesuaian terhadap ramalan-ramalan berdasarkan metode kuantitatif.

Dengan menggunakan metode peramalan ini diharapkan penjualan hijab SXProject di masa yang akan datang bisa diketahui sehingga produsen bisa mempersiapkan diri baik dari jumlah produk yang dipersiapkan terkait bahan baku atau pun modal dan jumlah karyawannya. Terkait penjualan, penelitian ini sudah dilakukan juga pada analisis permintaan mobil mitsubisi expander (Iwan et al, 2018), penjualan produk keripik pisang kemasan bungkus (Wardah \& Iskandar, 2016), penjualan produk kecap pada perusahaan kecap manalagi Denpasar Bali (Yanti et al, 2016).

\section{Bahan dan Metode:}

Penelitian ini merupakan penelitian yang bersifat deskriptif kuantitatif. Jenis data yang digunakan adalah data primer berupa data aktual penjualan hijab SXProject pada tahun 2018 Metode peramalan yang digunakan adalah metode peramalan Moving average (rata-rata bergerak) dua, tiga, dan 4 bulanan serta metode Exponential Smoothing (penghalusan eksponensial) dengan $\alpha=0,1, \alpha=0,15$ dan $\alpha=0,2$. Sementara untuk analisis tingkat kesalahan peramalannya menggunakan metode Mean Absolute Deviation (MAD), Mean Squared Error (MSE), dan Mean Absolute Percent Error (MAPE). Berikut penjelasan masing masing metode dan analisis tingkat kesalahan peramalan yang akan digunakan (Heizer, J. dan Rander, B., 2004).

\section{Moving Average (Rata-rata Bergerak)}

Peramalan rata-rata bergerak (moving average) menggunakan sejumlah data aktual masa lalu untuk menghasilkan peramalan. Rata-rata bergerak berguna jika diasumsikan bahwa permintaan pasar akan stabil sepanjang masa yang diramalkan. Secara matematis, rata-rata bergerak sederhana (merupakan prediksi permintaan periode mendatang) dinyatakan sebagai berikut:

$$
\text { Moving average }=\frac{\sum \text { permintaan } \mathrm{n} \text { periode sebelumnya }}{\mathrm{n}}
$$

di mana $\mathrm{n}$ adalah jumlah periode dalam rata-rata bergerak, sebagai contoh, 4, 5, atau 6 bulan, berarti rata-rata bergerak untuk 4,5 , atau 6 periode.

\section{Exponential \\ Smoothing \\ (Penghalusan \\ Eksponensial)}

Penghalusan eksponensial merupakan metode peramalan rata-rata bergerak dengan pembobotan yang canggih, namun masih digunakan. Metode ini menggunakan sangat sedikit pencatatan data masa lalu. Penelitian menggunakan metode ini sudah dilakukan sebelumnya dengan judul "Penerapan Metode Peramalan sebagai Alat Bantu untuk Menentukan Perencanaan Produksi di PT. SKK" (Wahyani \& Syaichu, 2015, Eris et al, 2014). Rumus penghalusan eksponensial dasar dapat ditunjukkan sebagai berikut:

$$
\begin{array}{cl}
F_{t}=F_{t-1}+\alpha & \left.A_{t-1}-F_{t-1}\right) \\
\operatorname{dimana} \mathrm{F}_{\mathrm{t}} & =\text { peramalan baru } \\
\mathrm{F}_{\mathrm{t}-1} & =\text { peramalan sebelumnya } \\
\alpha & =\text { konstanta penghalus }(0 \leq \alpha \leq 1) \\
\mathrm{A}_{\mathrm{t}-1} & =\text { permintaan actual periode lalu }
\end{array}
$$

\section{Menghitung Kesalahan Peramalan}

Keakuratan keseluruhan dari setiap model peramalan Moving average (rata-rata bergerak), Exponential Smoothing (penghalusan eksponensial) atau lainnya dapat dijelaskan dengan membandingkan nilai yang diramal dengan nilai aktual atau nilai yang sedang diamati. Jika Ft melambangkan peramalan pada periode $\mathrm{t}$, dan At melambangkan permintaan actual pada periode $t$, maka kesalahan peramalan (deviasi) adalah:

$$
\text { Kesalahan peramalan }=A_{t}-F_{t}
$$

Ada beberapa perhitungan yang biasa digunakan untuk menghitung kesalahan peramalan (forecast error) total. Perhitungan ini dapat digunakan untuk membandingkan model peramalan yang berbeda, juga untuk mengawasi peramalan, untuk memastikan peramalan berjalan dengan baik. Tiga perhitungan kesalahan peramalan yang terkenal adalah sebagai berikut:

\section{Mean Absolute Deviation (MAD)}

Nilai ini dihitung dengan mengambil jumlah nilai absolut dari tiap kesalahan peramalan dibagi dengan jumlah periode data $(n)$ :

$\mathrm{MAD}=\frac{\sum \mid \text { aktual }- \text { peramalan } \mid}{\mathrm{n}}$

\section{Mean Squared Error (MSE)}

Merupakan cara kedua untuk mengukur kesalahan peramalan keseluruhan. Mean Squared Error merupakan rata-rata selisih kuadrat antara nilai yang diramalkan dan yang diamati. Rumusnya adalah sebagai berikut:

MSE $=\frac{\sum(\text { kesalahan peramalan })^{2}}{n}$ 


\section{Mean Absolute Percent Error (MAPE)}

Masalah yang terjadi dengan MAD dan MSE adalah bahwa nilainya tergantung pada besarnya unsur yang diramal. Jika unsur tersebut dihitung dalam satuan ribuan, maka nilai MAD dan MSE bisa menjadi sangat besar. Untuk menghindari masalah ini dapat menggunakan Mean Absolute Percent Error (MAPE). MAPE dihitung sebagai rata-rata diferensiasi absolut antara nilai yang diramal dan aktual, dinyatakan sebagai persentase nilai aktual. Jika terdapat nilai yang diramal dan aktual untuk $n$ periode, MAPE dihitung sebagai berikut:

$\mathrm{MAPE}=\frac{100 \sum_{\mathrm{i}=1}^{\mathrm{n}} \mid \text { aktual }_{\mathrm{i}}-\text { ramalan }_{\mathrm{i}} \mid / \text { aktual }_{\mathrm{i}}}{\mathrm{n}}$

\section{Hasil dan Pembahasan}

SXProject merupakan salah satu merk hijab yang dijual secara online. Berikut ini adalah data penjualan hijab SXProject selama tahun 2018.

Tabel 1. Data Penjualan Hijab SXProject

\begin{tabular}{cc}
\hline Bulan & Total Penjualan \\
\hline Januari & 1000 \\
\hline Februari & 1143 \\
\hline Maret & 1372 \\
\hline April & 1453 \\
\hline Mei & 1407 \\
\hline Juni & 1500 \\
\hline Juli & 1428 \\
\hline Agustus & 1374 \\
\hline September & 1357 \\
\hline Oktober & 1473 \\
\hline November & 1409 \\
\hline Desember & 1426
\end{tabular}

Berdasarkan data penjualan tersebut, dengan menggunakan metode Moving average (rata-rata bergerak) 2 bulan, 3 bulan dan 4 bulan. Berikut ini adalah forecasting (peramalan) penjualan untuk tahun 2018 menggunakan Moving average 2 bulan, 3 bulan, dan 4 bulan (Yanti et al, 2016; Nugraha \& Suletra, 2017; Sudarman et al, 2016)

Tabel 2. Data Peramalan Penjualan dengan Menggunakan Metode Moving average 2 Bulan

\begin{tabular}{ccc}
\hline Bulan & Penjualan & $\begin{array}{c}\text { Moving average 2 } \\
\text { Bulan (MA2) }\end{array}$ \\
\hline Januari & 1000 & - \\
\hline Februari & 1143 & - \\
\hline Maret & 1372 & 1072 \\
\hline April & 1453 & 1258 \\
\hline Mei & 1407 & 1413 \\
\hline Juni & 1500 & 1430 \\
\hline Juli & 1428 & 1454 \\
\hline Agustus & 1374 & 1464
\end{tabular}

\begin{tabular}{cll}
\hline September & 1357 & 1401 \\
\hline Oktober & 1473 & 1366 \\
\hline November & 1409 & 1415 \\
\hline Desember & 1426 & 1441 \\
\hline
\end{tabular}

Tabel 3. Data Peramalan Penjualan dengan Menggunakan Metode Moving average 3 Bulan

\begin{tabular}{ccc}
\hline Bulan & Penjualan & $\begin{array}{c}\text { Moving average 3 } \\
\text { Bulan (MA3) }\end{array}$ \\
\hline Januari & 1000 & - \\
\hline Februari & 1143 & - \\
\hline Maret & 1372 & - \\
\hline April & 1453 & 1172 \\
\hline Mei & 1407 & 1323 \\
\hline Juni & 1500 & 1411 \\
\hline Juli & 1428 & 1453 \\
\hline Agustus & 1374 & 1445 \\
\hline September & 1357 & 1434 \\
\hline Oktober & 1473 & 1386 \\
\hline November & 1409 & 1401 \\
\hline Desember & 1426 & 1413 \\
\hline
\end{tabular}

Tabel 4. Data Peramalan Penjualan dengan Menggunakan Metode Moving average 4 Bulan

\begin{tabular}{ccc}
\hline Bulan & Penjualan & $\begin{array}{c}\text { Moving average 4 } \\
\text { Bulan (MA4) }\end{array}$ \\
\hline Januari & 1000 & - \\
\hline Februari & 1143 & - \\
\hline Maret & 1372 & - \\
\hline April & 1453 & - \\
\hline Mei & 1407 & 1242 \\
\hline Juni & 1500 & 1344 \\
\hline Juli & 1428 & 1433 \\
\hline Agustus & 1374 & 1447 \\
\hline September & 1357 & 1427 \\
\hline Oktober & 1473 & 1415 \\
\hline November & 1409 & 1408 \\
\hline Desember & 1426 & 1403 \\
\hline
\end{tabular}

Selain menggunakan metode moving average, perhitungan peramalan penjualan juga menggunakan metode Exponential Smoothing dengan $\alpha=0,1, \alpha=$ 0,15 dan $\alpha=0,2$ dengan asumsi forecasting penjualan pada Januari 2018 sama dengan aktual penjualan pada Januari 2018 yaitu 1000 buah hijab. Berikut ini adalah forecasting (peramalan) penjualan dengan menggunakan metode Exponential Smoothing $\alpha=0,1$, $\alpha=0,15$ dan $\alpha=0,2$.

Tabel 5. Data Peramalan Penjualan dengan Menggunakan Metode Exponential Smoothing $\alpha=0,1$

\begin{tabular}{ccc}
\hline Bulan & Penjualan & $\begin{array}{c}\text { Exponential } \\
\text { Smoothing } \alpha=0,1 \\
(\mathrm{ES}=0,1)\end{array}$ \\
\hline Januari & 1000 & 1000 \\
\hline Februari & 1143 & 1000 \\
\hline Maret & 1372 & 1143 \\
\hline April & 1453 & 1372 \\
\hline Mei & 1407 & 1453 \\
\hline
\end{tabular}




\begin{tabular}{cll}
\hline Juni & 1500 & 1407 \\
\hline Juli & 1428 & 1500 \\
\hline Agustus & 1374 & 1428 \\
\hline September & 1357 & 1374 \\
\hline Oktober & 1473 & 1357 \\
\hline November & 1409 & 1473 \\
\hline Desember & 1426 & 1409 \\
\hline
\end{tabular}

Tabel 6. Data Peramalan Penjualan dengan Menggunakan Metode Exponential Smoothing $\alpha=$ 0,15

\begin{tabular}{ccc}
\hline Bulan & Penjualan & $\begin{array}{c}\text { Exponential } \\
\text { Smoothing } \alpha=0,15 \\
(\mathrm{ES}=0,15)\end{array}$ \\
\hline Januari & 1000 & 1000 \\
\hline Februari & 1143 & 1000 \\
\hline Maret & 1372 & 1215 \\
\hline April & 1453 & 1451 \\
\hline Mei & 1407 & 1454 \\
\hline Juni & 1500 & 1383 \\
\hline Juli & 1428 & 1558 \\
\hline Agustus & 1374 & 1380 \\
\hline September & 1357 & 1346 \\
\hline Oktober & 1473 & 1537 \\
\hline November & 1409 & 1345 \\
\hline Desember & 1426 & \\
\hline
\end{tabular}

Tabel 7. Data Peramalan Penjualan dengan Menggunakan Metode Exponential Smoothing $\alpha=0,2$

\begin{tabular}{|c|c|c|c|}
\hline Bulan & Penjualan & \multicolumn{2}{|c|}{$\begin{array}{l}\text { Exponential Smoothing } \\
\quad \alpha=0,2(\mathrm{ES}=0,2)\end{array}$} \\
\hline Januari & 1000 & \multicolumn{2}{|c|}{1000} \\
\hline Februari & 1143 & \multicolumn{2}{|c|}{1000} \\
\hline Maret & 1372 & \multicolumn{2}{|c|}{1286} \\
\hline April & 1453 & \multicolumn{2}{|c|}{1458} \\
\hline Mei & 1407 & \multicolumn{2}{|c|}{1448} \\
\hline Juni & 1500 & \multicolumn{2}{|c|}{1366} \\
\hline Juli & 1428 & \multicolumn{2}{|c|}{1634} \\
\hline Agustus & 1374 & \multicolumn{2}{|c|}{1222} \\
\hline September & 1357 & \multicolumn{2}{|c|}{1526} \\
\hline Oktober & 1473 & \multicolumn{2}{|c|}{1188} \\
\hline November & 1409 & \multicolumn{2}{|c|}{1758} \\
\hline Desember & 1426 & \multicolumn{2}{|c|}{1060} \\
\hline \multicolumn{4}{|c|}{$\begin{array}{l}\text { Setelah menghitung peramalan penjualan denga } \\
\text { metode Moving average dan Exponential Smoothin } \\
\text { dilakukan perhitungan tingkat kesalahan denga } \\
\text { metode Mean Absolute Deviation (MAD), Mea } \\
\text { Squared Error (MSE), dan Mean Absolute Perce } \\
\text { Error (MAPE). } \\
\text { Tabel 8. Tingkat Kesalahan Perhitungan Forecasting }\end{array}$} \\
\hline Metode & MAD & MSE & MAPE \\
\hline MA2 & 86 & 15595 & 0,061 \\
\hline MA3 & 82 & 12621 & 0,057 \\
\hline MA4 & 69 & 8230 & 0,048 \\
\hline $\mathrm{ES}=0,1$ & 78 & 9704 & 0,057 \\
\hline $\mathrm{ES}=0,15$ & 81 & 9808 & 0,059 \\
\hline $\mathrm{ES}=0,2$ & 161 & 39983 & 0,116 \\
\hline
\end{tabular}

\section{Kesimpulan}

Berdasarkan perhitungan forecasting (peramalan) penjualan dengan menggunakan metode Moving average 2 bulan, 3 bulan, dan 4 bulan serta metode Exponential Smoothing dengan $\alpha=0,1, \alpha=0,15$ dan $\alpha$ $=0,2$ dengan perhitungan tingkat kesalahan menggunakan MAD, MSE ataupun MAPE menunjukkan bahwa tingkat kesalahan terkecil adalah dengan menggunakan metode forecasting Moving average 4 bulan yaitu tingkat kesalahan dengan metode $\mathrm{MAD}=69, \mathrm{MSE}=8230$, dan $\mathrm{MAPE}=0,048$. Hal ini sejalan dengan penelitian yang berjudul "Demand Forecasting pada Industri Jus Siap Minum" dengan tingkat kesalahan menggunakan MAPE sebesar 6\% (Supono, 2017). Namun berbeda jika metode moving average, exponential smooting, dan metode winter dibandingkan, hasilnya metode winter lebih baik digunakan (Heriansyah \& Hasibuan, 2017).

\section{Daftar Pustaka}

Eris, P. N., Nohe, D. A. \& Wahyuningsih, S. (2014). Peramalan dengan Metode Smoothing dan Verifikasi Metode Peramalan dengan Grafik Pengendali Moving Range (MR). Jurnal Eksponensial, 5(2), 203-210.

Heizer, J. dan Rander, B. (2004). Manajemen Operasi (edisi ketujuh). Salemba Empat: Jakarta.

Heriansyah, E. \& Hasibuan, S. (2017). Implementasi Metode Peramalan pada Permintaan Bracket Side Stand K59A. Jurnal PASTI, 12(2), 209-223.

Iwan, Rahayu, E. I. H. \& Yulianto, A. (2018). Analisa Peramalan Permintaan Mobil Mitsubishi Xpander dengan Tiga Metode Forecasting. Cakrawala, 18(2), 249-256.

Nugraha, E. Y \& Suletra, I. W. (2017). Analisis Metode Peramalan Permintaan Terbaik Produk Oxycan pada PT. Samator Gresik. Konferensi IDEC (pp. 414-422).

Sudarma, N.N., Andrawina, L., \& Aurachman, R. (2016). Penentuan Jumlah Perencanaan Permintaan Pelumas untuk Meminimasi Tingkat Kesalahan Peramalan Berdasarkan Peramalan Permintaan Pelumas pada PT. NYZ. EProciding of Engineering (pp: 3022-3028)

Supono, J. (2017). Demand Forecasting pada Industri Jus Siap Minum. Journal Industrial Manufacturing, 2(2), 76-84.

Yanti, N. P. L. P., Tuningrat, I. A. M. \& Wiranatha, A. A. P. A. S. (2016). Analisis Peramalan Penjualan Produk pada Perusahaan Kecap Manalagi Denpasar Bali. Jurnal Rekayasa dan Manajemen Agroindustri, 4(1), 72-81.

Wahyani, W. \& Syaichu, A. (2015). Penerapan Metode Peramalan sebagai Alat Bantu untuk Menentukan Perencanaan Produksi di PT. SKK. Spektrum Industri, 13(2), 133-140.

Wardah, S. \& Iskandar. (2016). Analisis Peramalan Penjualan Produk Keripik Pisang Kemasan Bungkus (Studi Kasus:Home Industry Arwana Food Tembilahan. Jurnal T. Ind, 11(3), 135-142. 